\title{
How Can We Improve the Solute and Fluid Transport Prescriptions in Hemodialysis to Improve Patient Outcomes?
}

\author{
Frank Gotch Peter Kotanko Nathan Levin
}

Renal Research Institute, New York, N.Y., USA

\section{Key Words}

Dialysis adequacy $\cdot \mathrm{Kt} / \mathrm{V} \cdot$ Phosphate kinetic modeling •

Bioimpedance

\begin{abstract}
Improvements in the dialysis prescription can only be achieved by changes in solute and water transport which provide better control of the metabolic uremic abnormalities that are amenable to dialysis. The key abnormalities identified here are protein catabolites, fluid and electrolyte balance, calcium and phosphorus balance and bone metabolism and acid-base balance. The history of the dialysis prescription is reviewed and changes which might improve the control of these metabolic systems are described. This review concludes there is no support for the recommendation of the routine application of long treatment time and routine use of hemodiafiltration.

Copyright $\odot 2013$ S. Karger AG, Basel
\end{abstract}

Fifty years after its inception maintenance dialysis therapy for end-stage renal failure continues to be associated with high rates of mortality and morbidity compared to age-matched normal subjects. Since the only rationale for dialysis therapy is to provide appropriate transport of solutes and water normally regulated by the kidneys, the continuing high mortality and morbidity will be addressed here in the context of how the dialysis solute and fluid transport prescriptions might be changed to improve outcome. This is a timely subject because there are currently recommendations that long dialysis treatment times $\left(\mathrm{t}_{\mathrm{d}}\right)$ of 4.0 or $4.5 \mathrm{~h}[1-3]$ and high-volume postdilution hemodiafiltration $\left(\mathrm{HDF}_{\mathrm{HV}}\right)$ [3] should be prescribed to all patients in order to improve clinical outcome. The clinical evidence base and the extent to which the pathophysiology of uremia is amenable to dialysis will be reviewed to address the validity of these recommendations and consideration of other solute transport recommendations that might be predicted to be better able to improve the quality of dialysis and clinical outcome.

\section{The Dialysis Dose: Blood Urea Nitrogen, $\mathbf{t}_{\mathrm{d}}, \mathrm{Kt} / \mathbf{V}_{\mathrm{U}}$ and the National Cooperative Dialysis Study}

Dialysis duration has been a focus of controversy ever since the exponent $\mathrm{Kt} / \mathrm{V}_{\mathrm{U}}$ was proposed to quantify the dialysis dose more than 25 years ago [4]. This dosing parameter successfully clarified the puzzling relationship of clinical outcome to blood urea nitrogen (BUN) in the National Cooperative Dialysis Study (NCDS) [4] which was the first and only randomized controlled trial (RCT) of clinical outcome with both prospective, rigorously defined dialysis doses and randomized levels of treatment time. When the NCDS was designed there were two com-

\section{KARGER \\ Fax +4161306 1234}

E-Mail karger@karger.com

www.karger.com (c) 2013 S. Karger AG, Basel

0253-5068/13/0353-0093\$38.00/0

Accessible online at: www.karger.com/bpu
Frank Gotch, MD

Renal Research Institute

207 East 94th Street, Suite 303

New York, NY 10128 (USA)

E-Mail Frank.Gotch.MD@fmc-na.com 


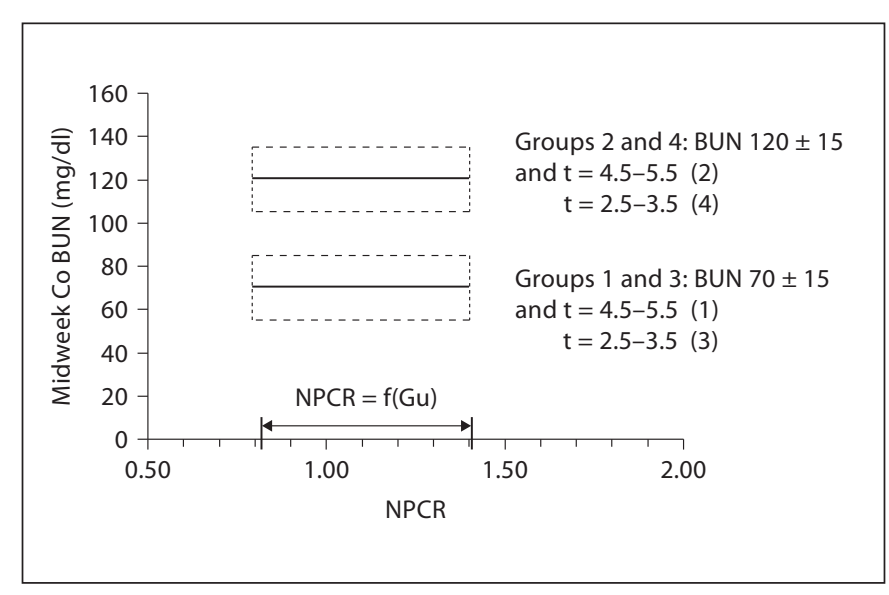

Fig. 1. The design of the NCDS. The protocol called for identical control of predialysis BUN as a function of NPCR in the low- and high-BUN groups with short and long treatment times as described above. $\mathrm{Co}=$ Control; $\mathrm{f}(\mathrm{Gu})=$ function of urea generation rate.

peting definitions of dialysis dose [1]: the level of predialysis BUN and [2] the concentration of theoretical toxic middle molecules, which were theorized to be inversely proportional to treatment time, particularly with the lowflux membranes in use at that time which had low middle molecule clearances. These two hypotheses were tested in the NCDS [5] by creating 4 arms or experimental groups in the study consisting of group 1 : low BUN $=70 \mathrm{mg} / \mathrm{dl}$, long $t_{d}=4.5-5.5 \mathrm{~h}$; group 3: low BUN $=70 \mathrm{mg} / \mathrm{dl}$, short $\mathrm{t}_{\mathrm{d}}=2.5-3.5 \mathrm{~h}$; group 2 : high $\mathrm{BUN}=120 \mathrm{mg} / \mathrm{dl}$, long $\mathrm{t}_{\mathrm{d}}=$ $4.5-5.5 \mathrm{~h}$, and group 4 : high BUN $=120 \mathrm{mg} / \mathrm{dl}$, short $\mathrm{t}_{\mathrm{d}}=$ 2.5-3.5 h. The design called for the use of urea kinetic modeling (UKM) to calculate the dialyzer clearance required and to assure that all patients maintained a protein intake of $1.10 \pm 0.30 \mathrm{~g} / \mathrm{kg} \mathrm{NBWt} /$ day where NBWt was normalized body weight defined as urea distribution volume divided by $0.58\left(\mathrm{~V}_{\mathrm{U}} / 0.58\right)$. As noted above, the study was guided by UKM which was used to calculate the normalized protein catabolic rate (NPCR), which in turn was used to monitor and adjust the dietary protein intake and to attempt to control NPCR $1.10 \pm 0.30$ for each patient [4]. UKM was also used to calculate urea distribution $\mathrm{V}_{\mathrm{U}}$ and the required dialyzer urea clearance $\left(\mathrm{K}_{\mathrm{U}}\right)$ to achieve the specified predialysis BUN and the group-specified $t_{d}$ for each patient in each of the 4 arms of the study. The unique dialysis prescription calculated for each patient was therefore defined kinetically and expressed quantitatively as $\mathrm{K} \cdot \mathrm{t} / \mathrm{V}_{\mathrm{U}}$ and this study design is depicted graphically in figure 1 in terms of BUN and
NPCR. An overview of the outcome in the NCDS is depicted in figure 2 .

Composite clinical outcome criteria were defined so that each patient in the 4 study arms could be categorized as a clinical outcome success or failure at the end of the study [4]. When the study was analyzed the observed success and failure scores were found to be distributed as plotted in figure $2 \mathrm{a}$. There were two major findings [1]. Over the study design domain (with respect to NPCR $0.8-1.4$ ) the two low-BUN arms had a low probability of failure (13\%) irrespective of $t_{d}$ [2]. The high-BUN arms had high probability of failure (52\%) irrespective of $t_{d}$, and in patients with NPCR $<0.80$, there was a high failure rate of $72 \%$ unrelated to BUN [3]. Thus, as shown in figure $2 \mathrm{a}$, patients with protein intake $<0.80 \mathrm{~g} / \mathrm{kg} /$ day constituted a fifth unintended study arm, group 5 , which was of considerable consequence. The high rate of failure in this group was initially considered to be nutritionally related to very low protein intake [6] but, since the level of $\mathrm{BUN}$ is a linear function of urea generation and hence NPCR, with the slope determined by $\exp (-\mathrm{Kt} / \mathrm{V})$, it could be predicted from further consideration of these data that in this study design the dose of dialysis expressed as $\mathrm{Kt} / \mathrm{V}_{\mathrm{U}}$ would be very low for all patients with low NPCR irrespective of BUN. These relationships were explicitly examined by solving the urea model over a wide range of BUN as a function of NPCR and $\mathrm{Kt} / \mathrm{V}_{\mathrm{U}}$ [4] to generate the family of linear functions shown in figure $2 \mathrm{~b}$. This kinetic plot was superimposed on the NCDS clinical outcome plot [4] in figure $2 \mathrm{a}$, with results depicted in figure 3. In figure 3 it can be seen that the dialysis dose $\mathrm{Kt} / \mathrm{V}_{\mathrm{U}}=1.00$ clearly separated the two lowfailure-rate groups 1 and 3 from the three high-failurerate groups 2, 4 and 5. It also shows that because of the study design, all patients with NPCR $<0.80$ were prescribed low levels of $\mathrm{Kt} / \mathrm{V}_{\mathrm{U}}$ which was associated with a high-failure rate irrespective of the BUN level due to low $\mathrm{Kt} / \mathrm{V}_{\mathrm{U}}$.

Thus the puzzling clinical outcome results in the NCDS relative to the initial hypotheses were clearly explained by UKM analysis as sketched in figure 4 . In figure 4 it is clear that the level of BUN cannot be interpreted without knowing the NPCR since both are required to specify the locus of $\mathrm{Kt} / \mathrm{V}_{\mathrm{U}}$ corresponding to any BUN. Inadequate dialysis may occur with BUN ranging from 40 to $140 \mathrm{mg} / \mathrm{dl}$ depending on the NPCR. As depicted in figure 5, UKM can provide an interesting insight into the beginning of the many years of controversy about the relationship of BUN to clinical symptoms that first erupted in the early 19th century. Bostock [8] reported a group of 
Fig. 2. Results of NCDS (a) and solution of the urea model (b). PF = Probability of failure.

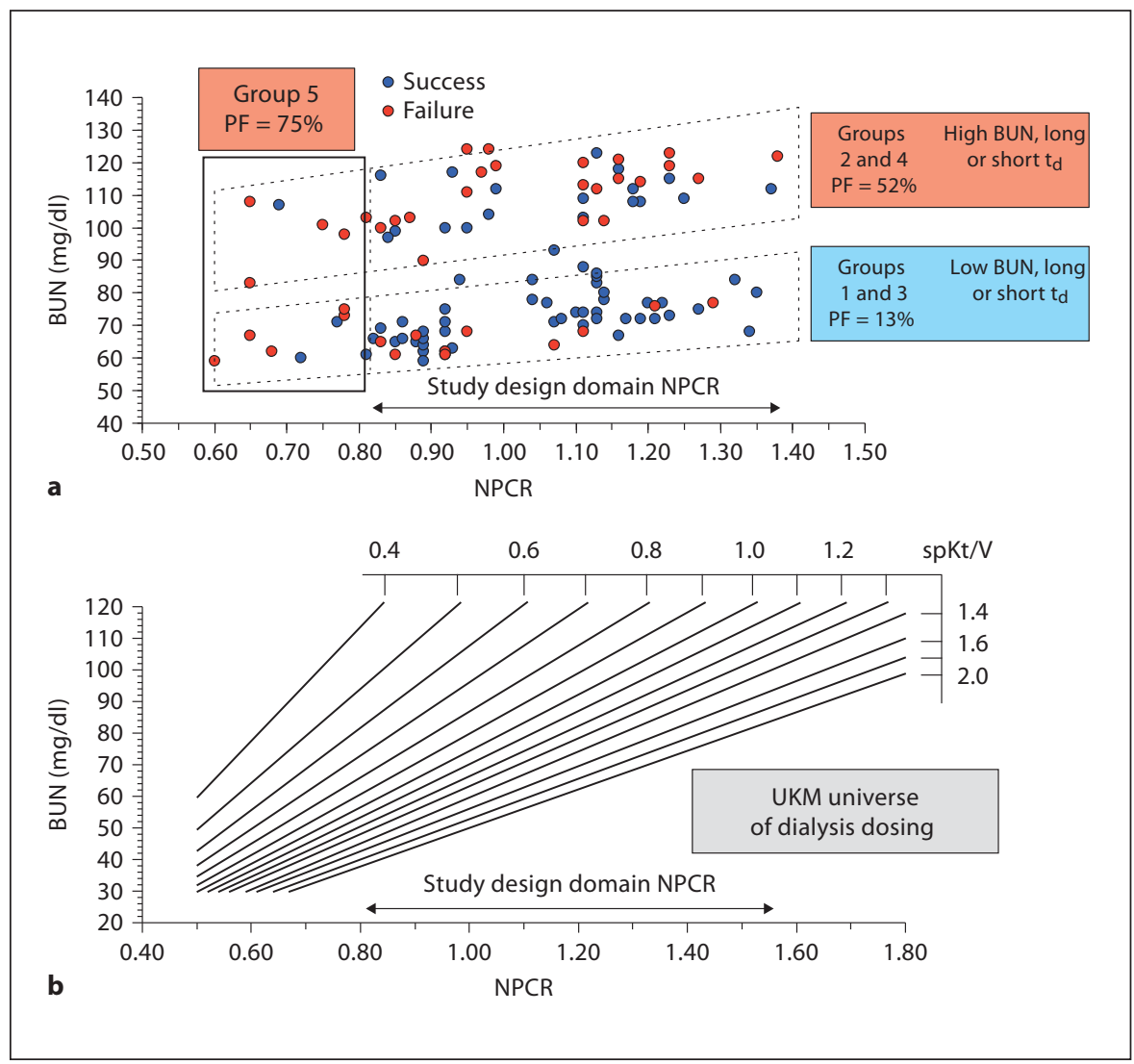

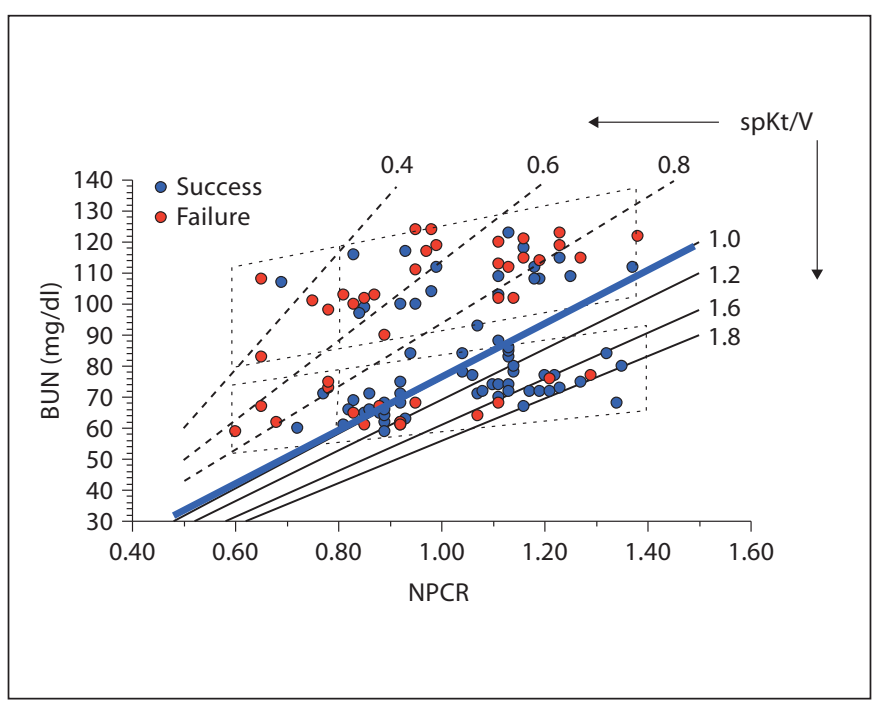

Fig. 3. NCDS outcome results with superimposed Kt/V grid indicates outcome failure was virtually eliminated when $\mathrm{Kt} / \mathrm{V}>0.80$ and $\mathrm{Kt} / \mathrm{V}=1.00$ completely separated all three failure groups $(2$, 4 and 5) from those groups with successful outcome (1 and 3).

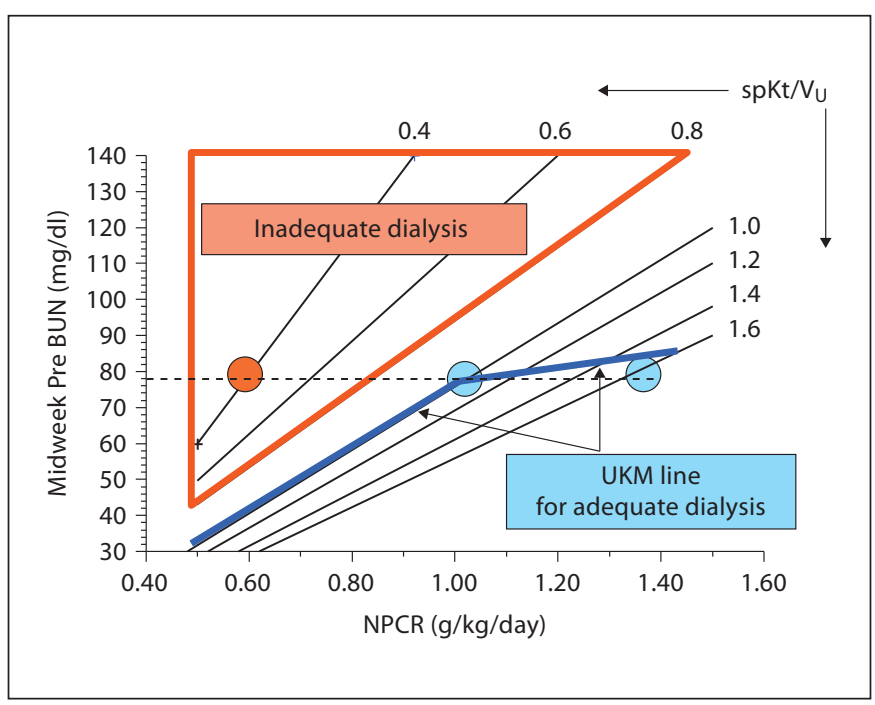

Fig. 4. When Kt/V was superimposed on the NCDS outcome data it was clear that failure was associated with $\mathrm{Kt} / \mathrm{V}<0.80$ and that the level of BUN could not be used to determine the dose of dialysis. A BUN $80 \mathrm{mg} / \mathrm{dl}$ could represent very low protein intake and very low dialysis dose or just the opposite very high intake and very high dose. Pre $=$ Predialysis .

Blood Purif 2013;35:93-105 


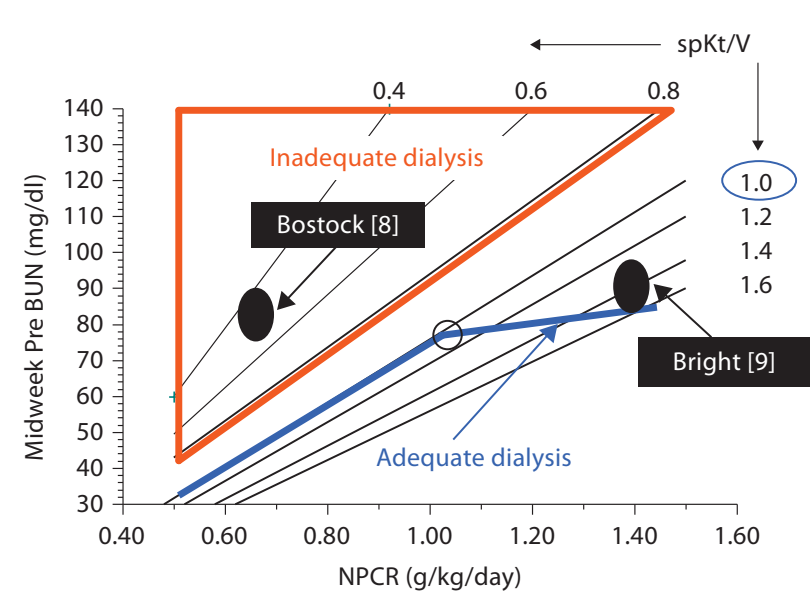

Fig. 5. UKM provides insight into the controversy over BUN that first erupted in the early part of the 19th century. Bostock reported high BUN associated with severe clinical uremia. Ten years later Bright reported a group of patients with high BUN and no clinical symptoms. The UKM plot provides a clear explanation for this puzzle nearly 200 years ago. (Bostock's patients had very low renal urea clearance and low NPCR while Bright's patients had higher renal urea clearance and good appetite.) Pre = Predialysis.

untreated patients with clinical uremia and high BUN and described the syndrome of uremia of these patients. Ten years later Bright [9] reported a group of untreated patients with the same level of BUN who were clinically well. Figure 5 indicates that Bostock's patients probably had far advanced renal failure with low NPCR while Bright's patients had substantially more renal function and high NPCR, thus resolving this controversy of two centuries ago. The plot in figure 4 is very useful for monthly review of dialysis therapy in individual patients since it shows both the dose of dialysis and the NPCR which provides a quantitative estimate of dietary protein intake as well as $\mathrm{Kt} / \mathrm{V}_{\mathrm{U}}$ over time. It is essential to have a reliable measure of the actual grams of protein intake (protein catabolic rate, PCR) in order to meaningfully discuss dietary protein intake with patients who have unacceptably low or high protein intake. The PCR provides a way to show patients what their serving sizes must actually be to account for the high or low intakes documented with the PCR as illustrated in figures 6 and 7. Figure 6 depicts a not uncommon problem where there is poor compliance with the dietary protein intake. This can be very explicitly addressed with UKM as shown. A common problem at the inception of dialysis therapy is pro- tein calorie malnutrition due a period of anorexia and poor intake prior to institution of dialysis. That this also continues to be present in a substantial number of patients on therapy has been emphasized as a major problem with the recommendation to the patient 'eat, eat, eat but not salt' [1]. However this well-worded advice did not include the use of UKM to monitor if the patient is following the advice. As shown in figure 7 it is common in such patients to continue with poor protein intake that can only be recognized and addressed with UKM. Unfortunately clinical use of UKM after the NCDS analysis was published (and continuing up to the present time) is most often based entirely on approximation equations $[10,11]$ which provide an estimate of the ratio $\mathrm{Kt} / \mathrm{V}$ or urea reduction ratio (URR) with no attention paid to NPCR, PCR, $\mathrm{V}_{\mathrm{U}}$ and $\mathrm{K}_{\mathrm{U}}$. As will be discussed below, NPCR, PCR and $V_{U}$ are the kinetic cornerstones for quantitative anal$y$ sis of several other very important solute systems in uremia: $\mathrm{Ca}^{2+}$ and $\mathrm{P}$ metabolism, acid-base balance and $\mathrm{Na}^{+}$ balance, all of which must be controlled as well as possible by dialysis therapy.

\section{The Optimal Kt/V Controversy}

Almost immediately after $\mathrm{Kt} / \mathrm{V}_{\mathrm{U}}$ was proposed as a generalized kinetic-based dose parameter [4] the level of optimal Kt/ $\mathrm{V}_{\mathrm{U}}$ became controversial and that controversy continued for 25 years until the HEMO study was published. The NCDS outcome data were originally interpreted as a discontinuous function with an abrupt decrease in mortality in the low-BUN groups as shown in figure 8 where it can be seen that failure was much lower in the low-BUN goups 1 and 3 compared to 2, 4 and 5. In sharp contrast, others chose to interpret this as a continuous function through all five groups with an exponential decrease in failure implying optimal dialysis required much higher $\mathrm{Kt} / \mathrm{V}_{\mathrm{U}}$. This interpretation was then strongly reinforced by Dialysis Outcomes and Practice Patterns Study (DOPPS) observational studies over 20 years which appeared to show an ever-improving outcome as $\mathrm{Kt} / \mathrm{V}_{\mathrm{U}}$ increased to very high levels.

\section{The Roles of DOPPS and HEMO in the Clinical Value of $\mathrm{Kt} / \mathrm{V}_{\mathrm{U}}$}

DOPPS reports $[12,13]$ showed an ever-improving outcome as $\mathrm{Kt} / \mathrm{V}_{\mathrm{U}}$ increased to very high levels of 2.5 and resulted in a widely held belief that $\mathrm{Kt} / \mathrm{V}_{\mathrm{U}}$ was the single 


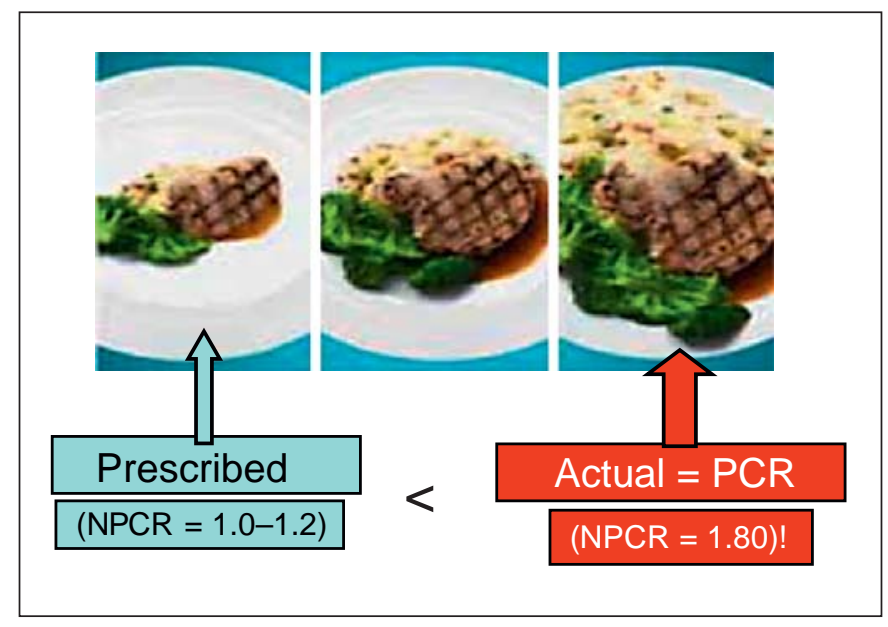

Fig. 6. Many patients underestimate dietary protein intake. With UKM and calculation of PCR this can be quantified for patient counseling.

most important index of the effective dose of dialysis since it correlated so well with outcome and the higher the $\mathrm{Kt} / \mathrm{V}_{\mathrm{U}}$ the better the outcome. Publication of the HEMO study results [14] and the accompanying paper on Dose Targeting Bias [15] revealed a basic flaw in the design of DOPPS observational study analyses showing these analyses of outcome relative to dose became selffulfiling prophesies because of unrecognized comorbidities associated with an analysis of outcome by achieved dose stratification. The HEMO study was a prospectively RCT and clearly showed that outcome in the high-dose arm was not different from outcome in the standard-dose arm. However, the external safety monitoring committee was concerned about the standard-dose arm since by the time the study actually got underway this dose was below the most recently reported DOPPS data showing improved clinical outcome. Consequently the monitoring committee requested the data coordinating center to examine outcome in the low-dose arm after stratifying patients into quintiles of achieved $\mathrm{Kt} / \mathrm{V}_{\mathrm{U}}$. That analysis showed a striking decrease in mortality as achieved Kt/ $\mathrm{V}_{\mathrm{U}}$ increased in this group. This could have easily resulted in termination of the study and the conclusion reached that clinical outcome was still improving with spKt/ $\mathrm{V}_{\mathrm{U}}$ $>2$ and that $\mathrm{Kt} / \mathrm{V}_{\mathrm{U}}<2$ was not an optimal therapy. However, an identical stratified analysis of the high-dose group was done and showed exactly the same thing as depicted in figure 9.

Figure 9 reveals the inherent fallacy in the DOPPS study methodology in which clinical outcome is analyzed

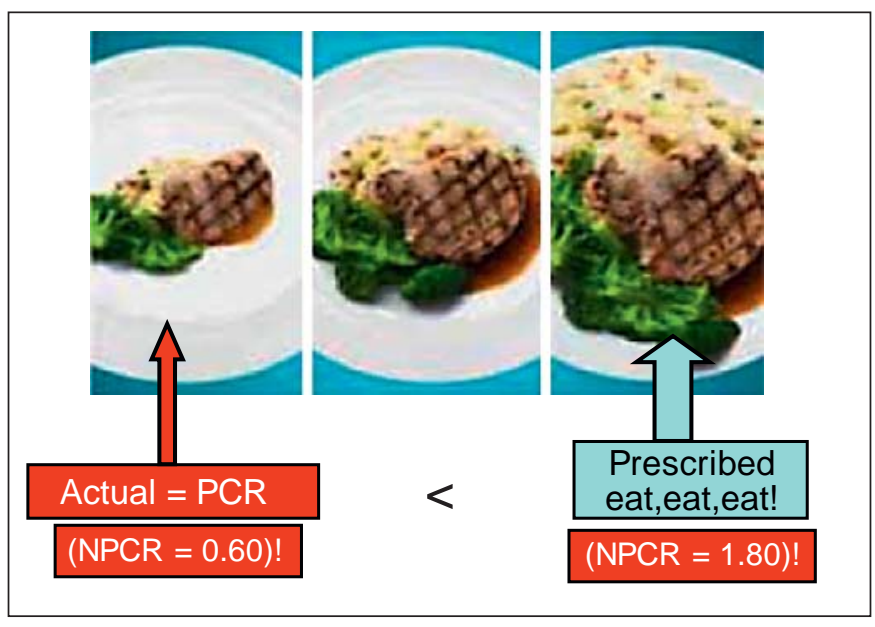

Fig. 7. Illustration of UKM demonstration of failed prescription of high-protein energy intake.

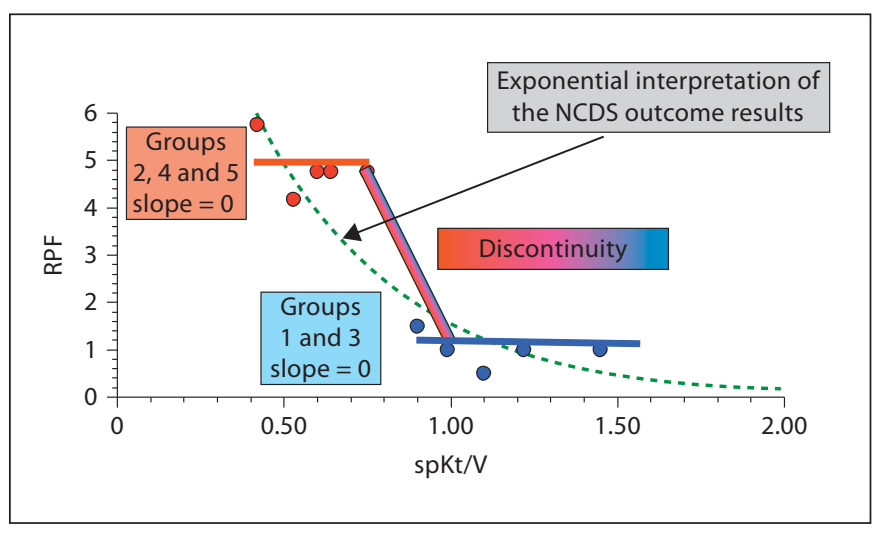

Fig. 8. The 25-year controversy about clinical outcome and Kt/V. We interpreted this as discontinuous function with a break point at $0.8-1.0$ where the high-BUN groups sequed into the high-BUN groups. Others tried to lump all four groups together as a continuous function with mortality exponentially decreasing forever. $\mathrm{RPF}=$ Relative probability of failure.

as a function of achieved $\mathrm{Kt} / \mathrm{V}_{\mathrm{U}}$. In this kind of analysis unrecognized comorbidities stratify inversely with the achieved dose parameter and severely confound the clinical outcome analyses. Unfortunately the powerful effect of dose targeting bias on analysis of clinical outcome data is still not widely appreciated and will be illustrated further below. In the case of $\mathrm{Kt} / \mathrm{V}_{\mathrm{U}}$, the renal community has tended to conclude that the HEMO showed that $\mathrm{Kt} / \mathrm{V}_{\mathrm{U}}$ has little clinical meaning as a dosing parameter since 
Fig. 9. Reconciliation of DOPPS studies of dialysis clinical outcome as a function of the achieved dose with outcome found in the HEMO RCT. A stratified achieved dose analysis of HEMO would have shown that outcome was continuing to improve up to Kt/V of 2.0. RRM = Relative risk of mortality; Std = standard dose; HD = high dose.

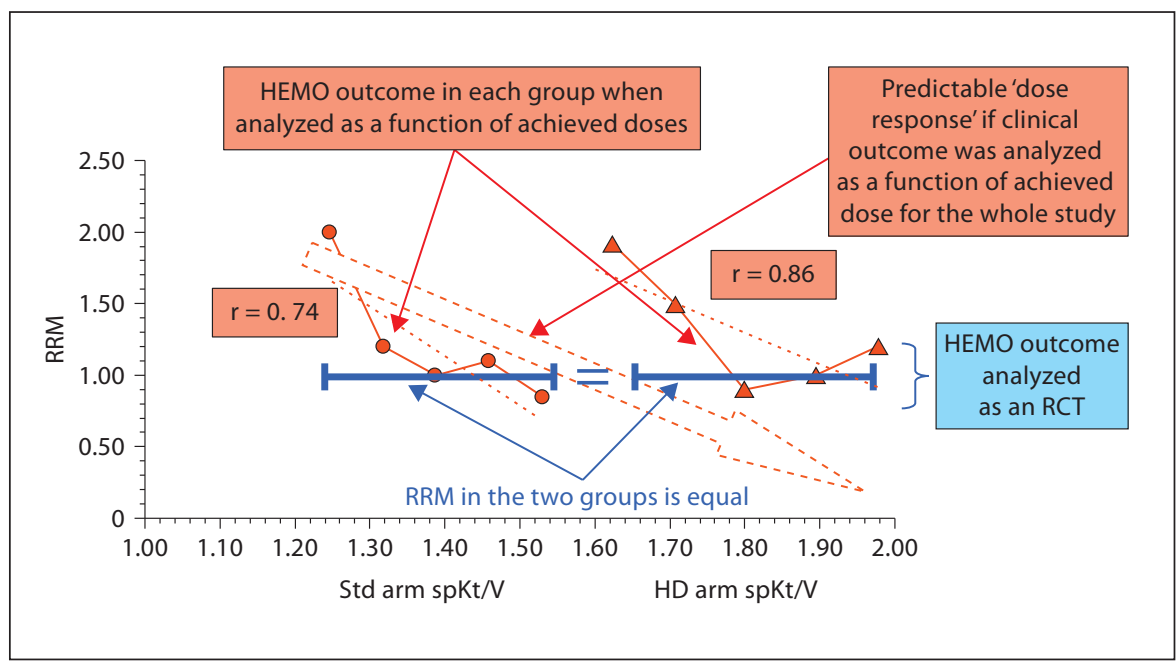

Fig. 10. The observed mortality rate varied much more between countries than it did as a function of treatment time in these DOPPS data. Nonetheless these data were lumped together to support the generalization that mortality rate decreases $7 \%$ for every 30-min increase in treatment time. The NCDS was an RCT and showed no effect of $t_{d}$ on outcome over a much wider range.

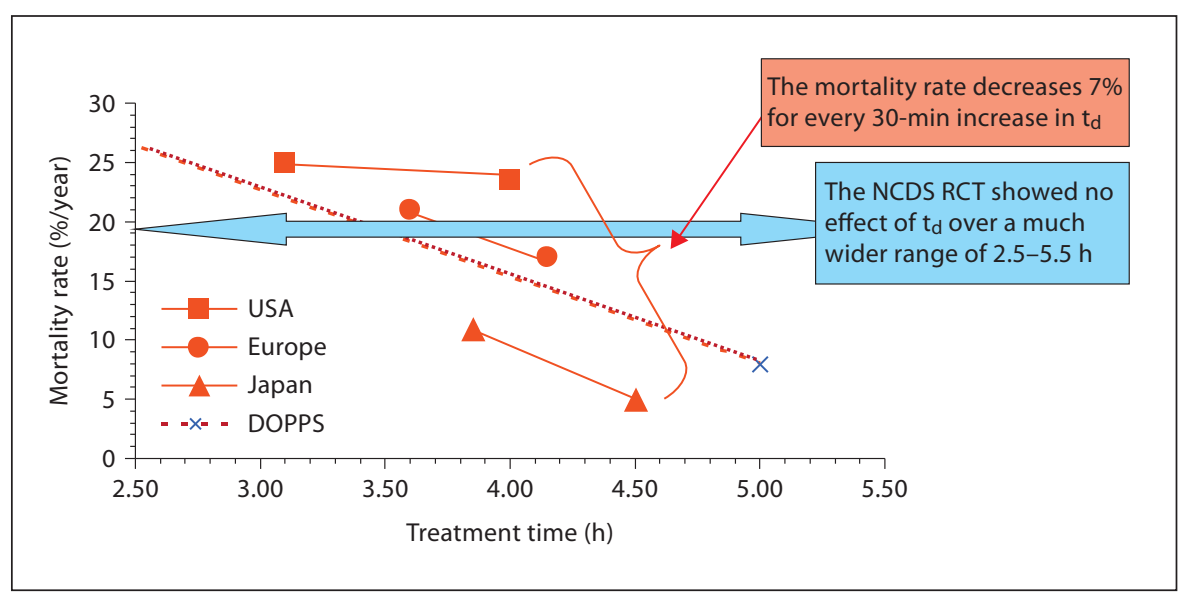

there was no difference in outcome of what DOPPS had previously reported was a very wide range of effective dose $\left(\mathrm{Kt} / \mathrm{V}_{\mathrm{U}}\right)$ as illustrated in figure 9. In fact, the HEMO results are consistent with the conclusion reached in the analysis of NCDS more than 25 years ago [4] that there was no improvement in outcome over the range $1.00 \leq$ $\mathrm{spKt} / \mathrm{V}_{\mathrm{U}} \leq 1.40$ (fig. 4).

\section{What Evidence Is There to Support Routine Prescription of Long $t_{d}$ ?}

This recommendation is supported only by observational studies. The strongest statement in this regard is from a DOPPS study in which it was concluded that mortality rate decreases $7 \%$ globally for every 30 -min in- crease in treatment time [13]. This study was comprised of data from the USA, Europe and Japan which are shown in figure 10.

The range and distribution of data points reported for each country are plotted and the dotted line is the DOPPS regression of these combined data into the single generalization noted above. Simple inspection shows these data do not convincingly support such a generalized relationship of $t_{d}$ to mortality although they are widely quoted to do so [1-4]. In the DOPPS data above the effect of $t_{d}$ on mortality for the US would be virtually negligible - about $1 \%$ per $5 \mathrm{~h}$.

The NCDS is the only RCT to study the effect of $t_{d}$ on outcome and it is widely believed to have indicated that shorter $t_{d}$ was an important predictor of increased mortality but was falsely interpreted to be negative because of 
Fig. 11. The NCDS design called for identical distributions of $\mathrm{spKt} / \mathrm{V}$ at $\mathrm{t}_{\mathrm{d}}=2.5-$ $3.5 \mathrm{~h}$ and $\mathrm{t}_{\mathrm{d}}=4.5-5.5 \mathrm{~h}$ as illustrated here. In this plot values for short $t_{d}$ are plotted as virtually identical to those with long $t_{d}$ which the study design called for.

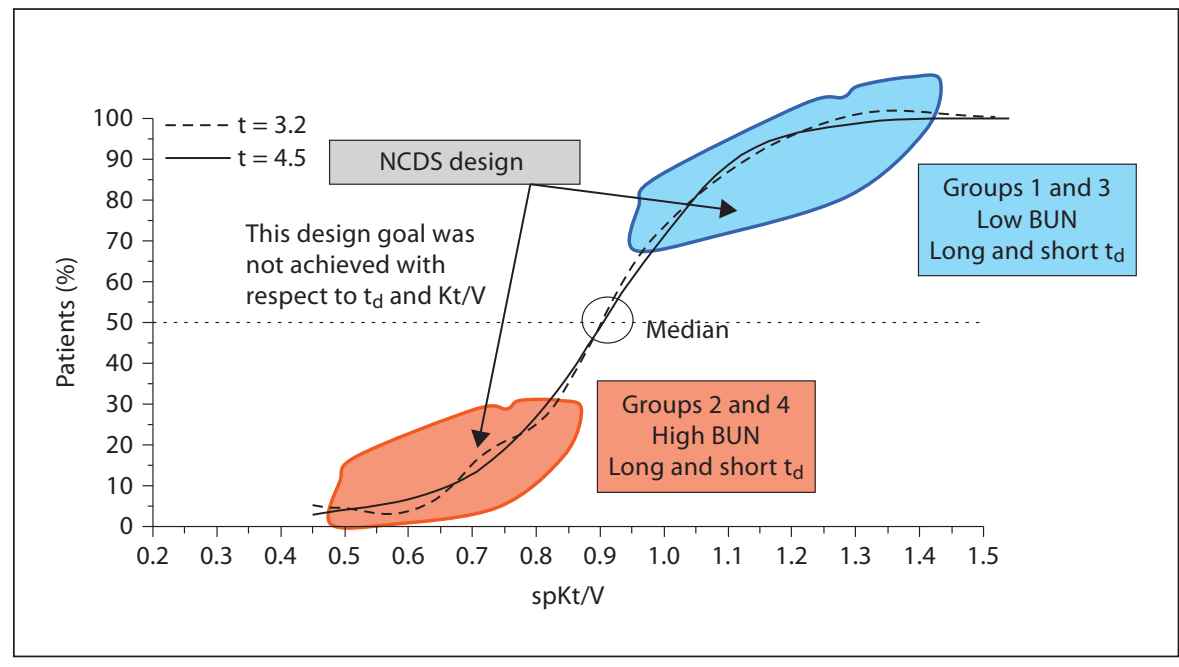

Fig. 12. The marginal $\mathrm{p}=0.06$ in the NCDS for $\mathrm{RRF}=f(\mathrm{t})$ was clearly of no significance because of the highly significant correlation of $\mathrm{Kt} / \mathrm{V}$ to treatment time due to the inability to deliver high $\mathrm{Kt} / \mathrm{V}$ with short treatment time with the dialyzers available at the time of the NCDS.

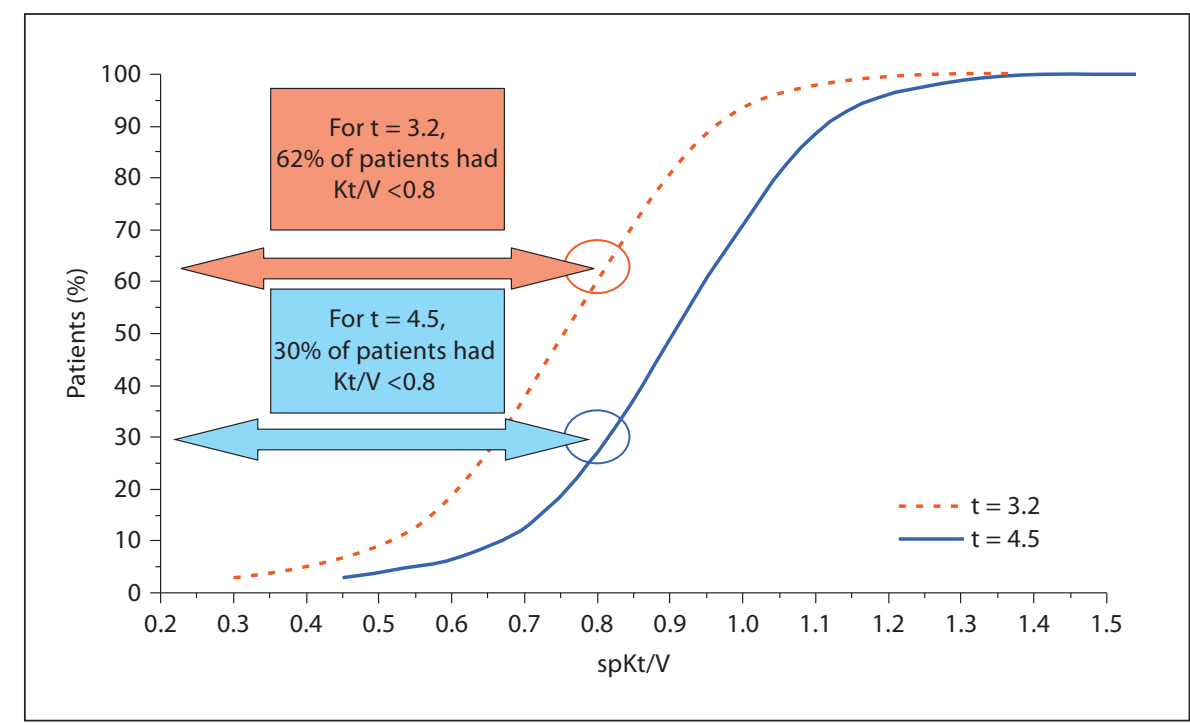

the marginal $p=0.06$ and therefore 'misled' the dialysis community for 25 years [16].

A major flaw in the NCDS study of $t_{d}$ has been reported previously [4] but largely ignored [1-3]. As detailed above, groups 1 and 3 were to have low BUN (high Kt/ $\mathrm{V}_{\mathrm{U}}$ ) and short treatment times while groups 2 and 4 were to have high $\mathrm{BUN}$ (low $\mathrm{Kt} / \mathrm{V}_{\mathrm{U}}$ ) with long and short treatment times. These design goals were not achieved since the inefficient dialyzers available at the time of the NCDS study, nearly 30 years ago now, made it impossible to reliably achieve in all patients the targeted $\mathrm{Kt} / \mathrm{V}$ in the shorttime, low-BUN (high $\mathrm{Kt} / \mathrm{V}_{\mathrm{U}}$ ) groups [17] as is illustrated in figures 11 and 12 . Figure 11 shows the design goal with identical Kt/V distribution and time distributed over a very wide range from 2.5 to $5.5 \mathrm{~h}$. This was a powerful design (which has never been duplicated) to test the effect of treatment time on outcome but unfortunately the design goal was not achieved for the reason given above. The actual distribution of the data is shown in figure 12. It can be seen in figure 12 that the frequency of $\mathrm{Kt} / \mathrm{V}<0.80$ (which was strongly correlated with a greatly increased risk of failure) in the short-time groups was twice that in the long-time groups. A marginal $p=0.06$ could not even remotely be considered significant with this distribution of $\mathrm{Kt} / \mathrm{V}_{\mathrm{U}}$. In keeping with these results is the recent publication of the outcome results in the long nocturnal arm 


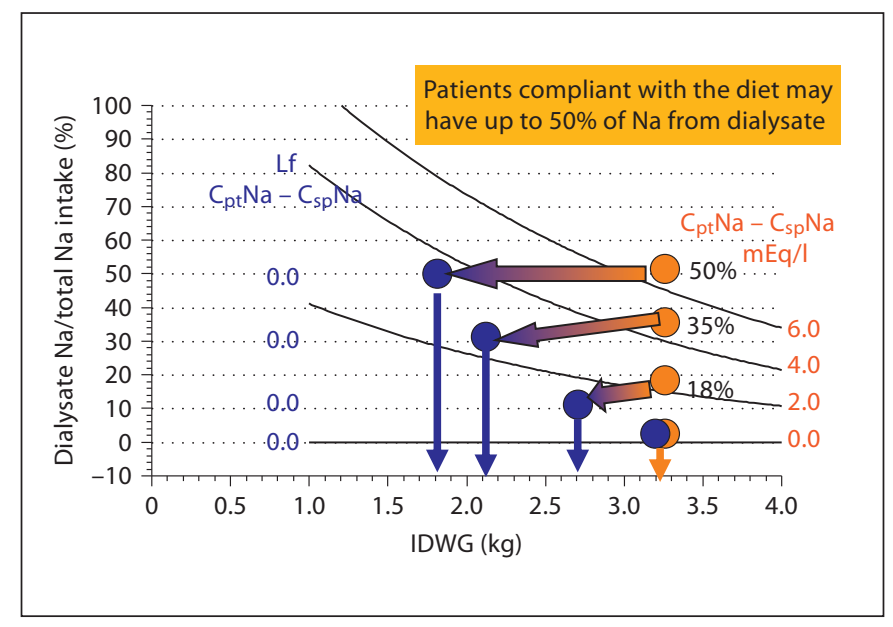

Fig. 13. Intradialytic $\mathrm{Na}$ loading as percent of total $\mathrm{Na}$ loading (dialysis + diet) calculated as a function of $\left(\mathrm{C}_{\mathrm{pt}} \mathrm{Na}-\mathrm{C}_{\mathrm{sp}} \mathrm{Na}\right)$ and IDWG. Note that IDWG $3.0 \mathrm{~kg}$ with a gradient $5 \mathrm{mEq} / \mathrm{l}$ would be reduced to $1.5 \mathrm{~kg}$ if the gradient were reduced to zero.

of the NIH Frequent Hemodialysis Network (FHN) study [18]. There were no objective improvements in outcome despite the enormous increase of $t_{d}$ to $5-6 \mathrm{~h}$ and a frequency to 6 times per week. Although these data were confounded by significant residual urine volumes, they do provide compelling evidence against the recommendation of a routine 3 times a week prescription of long $t_{d}$ based on observational studies [1-3].

\section{What Is the Evidence Supporting Routine Prescription of $\mathrm{HDF}_{\mathrm{HV}}$}

RCTs of hemodiafiltration have not shown improvement in outcome with this therapy compared to low- or high-flux hemodialysis $[19,20]$. However outcome in the subset analysis of the two RCTs after stratification by achieved replacement volume revealed improved outcome with increasing replacement volume $[19,20]$. It seems quite remarkable that these analyses of outcome with stratification of achieved replacement volume are being made and reported about $\mathrm{HDF}_{\mathrm{HV}}$ so shortly after the systematic error of dose targeting bias in DOPPS was reported. Examination of outcome after stratification of hemodiafiltration by achieved replacement volume is an analogue of the analysis of outcome as a function of stratification by achieved Kt/ $\mathrm{V}_{\mathrm{U}}$ in DOPPS studies and clearly shows that the lesson of dose targeting bias in HEMO has not been generally appreciated. What appears to have happened is that the
HEMO results have resulted in a backlash to the DOPPS spiral of ever-improving outcome with increasing $\mathrm{Kt} / \mathrm{V}_{\mathrm{U}}$ which resulted in the conclusion that $\mathrm{Kt} / \mathrm{V}_{\mathrm{U}}$ is not a useful parameter of dosage, instead of recognizing that there is a ceiling on improved outcome at $\mathrm{eKt} / \mathrm{V}$ in the range of 1.21.4 and that lower doses carried adverse outcomes. Routine automated measurement of conductivity-based $\mathrm{Kt} / \mathrm{V}_{\mathrm{U}}$ is a powerful tool to provide continuous online screening for technical errors in dialysis [21] such as errors in blood flow rate, dialyzer clotting and recirculation.

\section{How Can the Prescription of Fluid Removal in Dialysis Therapy Be Improved?}

Frequent recommendations in this regard [1-3] are to limit the rate of ultrafiltration to $10 \mathrm{ml} / \mathrm{min}$, avoid hypotension and prescribe a low-salt diet.

There is virtually no consideration given in the literature to (1) calculation of the actual amount of sodium $(\mathrm{Na})$ accumulated during and between dialyses, (2) choosing the optimal dialysate $\mathrm{Na}$ for individual patients and (3) assuring accurate delivery of the prescribed dialysate $\mathrm{Na}$. In analogy with the discussion above with respect to counseling patients about dietary protein intake, it is very difficult to discuss dietary $\mathrm{Na}$ without an accurate estimate of how much $\mathrm{Na}$ the patient is actually currently ingesting. Detailed derivations of equations to rigorously calculate $\mathrm{Na}$ and water accumulation and removal during and between dialyses and the magnitude of change in extracellular fluid volume $\left(\mathrm{V}_{\mathrm{ecw}}\right)$ have been published [22]. Key publications underlying the calculations are the paper by Edelman et al. [23] on osmotic relationships between plasma $\mathrm{Na}$ $\left(\mathrm{C}_{\mathrm{p}} \mathrm{Na}\right)$ and total body water (urea volume, $\mathrm{V}_{\mathrm{U}}$ ) published 50 years ago and the recent Keen papers [24, 25] on the plasma $\mathrm{Na}$ set point concentration $\left(\mathrm{C}_{\mathrm{sp}} \mathrm{Na}\right)$ which determines the normal plasma $\mathrm{Na}$ concentration $\left(\mathrm{C}_{\mathrm{p}} \mathrm{Na}\right)$ for individual patients. The predialysis $\mathrm{C}_{\mathrm{p}} \mathrm{Na}$ is equal to the $\mathrm{C}_{\mathrm{sp}} \mathrm{Na}$ and dialysate inlet $\mathrm{Na}\left(\mathrm{C}_{\mathrm{di}} \mathrm{Na}\right)$ should always be matched to that value in order to avoid inappropriate diffusive uptake (or loss) from a dialyzer Na gradient. The net flux of $\mathrm{Na}(\mathrm{mg})$ during dialysis $\left(\mathrm{J}_{\mathrm{d}} \mathrm{Na}\right)$ can be reliably calculated from

$$
\mathrm{J}_{\mathrm{d}} \mathrm{Na}=23 \cdot\left(\mathrm{C}_{\mathrm{pt}} \mathrm{Na}-\mathrm{C}_{\mathrm{sp}} \mathrm{Na}\right) \cdot \mathrm{V}_{\mathrm{Ut}}
$$

where $\mathrm{C}_{\mathrm{pt}} \mathrm{Na}$ is the equilibrated end dialysis $\mathrm{C}_{\mathrm{p}} \mathrm{Na}$ and $\mathrm{V}_{\mathrm{Ut}}$ is end dialysis $\mathrm{V}_{\mathrm{U}}$.

It must be noted that the calculation in equation 1 only applies if $\mathrm{C}_{\mathrm{di}} \mathrm{Na}$ has differed from $\mathrm{C}_{\mathrm{sp}} \mathrm{Na}$. The interdia- 
Fig. 14. Ideally $\mathrm{C}_{\mathrm{di}} \mathrm{Na}$ should cover the same range as the distribution of $\mathrm{C}_{\mathrm{sp}} \mathrm{Na}$ so they can be matched in individual patients to avoid diffusive Na flux.

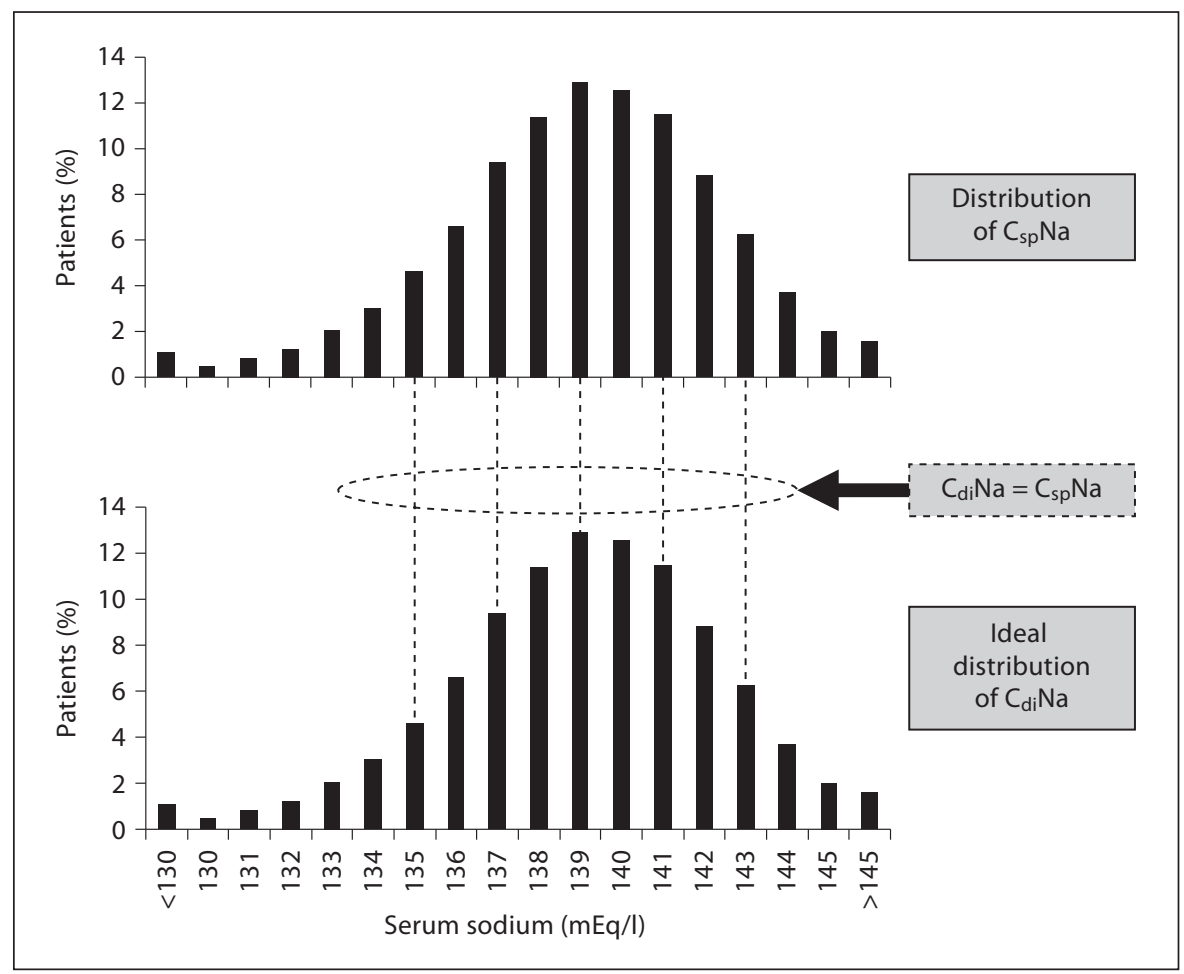

lytic intake of dietary $\mathrm{Na}\left(\mathrm{J}_{\text {Diet }} \mathrm{Na}, \mathrm{mg}\right)$ and water are isonatric with the set point concentration and can be calculated from the expression

$$
\mathrm{J}_{\text {Diet }} \mathrm{Na}=23 \cdot\left[\mathrm{IDWG} \cdot \mathrm{C}_{\mathrm{sp}} \mathrm{Na}-\left(\mathrm{C}_{\mathrm{pt}} \mathrm{Na}-\mathrm{C}_{\mathrm{sp}} \mathrm{Na}\right) \cdot \mathrm{V}_{\mathrm{Ut}}\right]
$$

where IDWG represents interdialytic weight gain. With ideal therapy $\mathrm{C}_{\mathrm{di}} \mathrm{Na}=\mathrm{C}_{\text {sp }} \mathrm{Na}$ and dietary $\mathrm{Na}$ is simply calculated from

$$
\mathrm{J}_{\text {Diet }} \mathrm{Na}=23 \cdot \mathrm{IDWG} \cdot \mathrm{C}_{\mathrm{sp}} \mathrm{Na}
$$

Armed with accurate estimates of current dietary $\mathrm{Na}$ intake, the dietician can undertake quantitative dietary counseling with the patient to improve patient understanding of dietary salt content and often achieve improved management of $\mathrm{Na}$ intake which drives fluid intake and IDWG.

The effect of matching of $\mathrm{C}_{\mathrm{di}} \mathrm{Na}$ with $\mathrm{C}_{\mathrm{sp}} \mathrm{Na}$ is illustrated in figure 13 . The data in figure 13 were calculated for average patient and dialyzer parameters using the recently published $\mathrm{Na}$ mass balance relationships [22]. Note that a $3-\mathrm{kg}$ IDWG with $\mathrm{C}_{\mathrm{di}} \mathrm{Na}$ gradient of $6 \mathrm{mEq} / \mathrm{l}$ would be reduced to $1.5 \mathrm{~kg}$ with $\mathrm{C}_{\mathrm{di}} \mathrm{Na}$ gradient reduced to zero. Since the $\mathrm{C}_{\mathrm{sp}} \mathrm{Na}$ is distributed over the range of $135-145 \mathrm{mEq} / \mathrm{l}$, prescribing a single $\mathrm{C}_{\mathrm{di}} \mathrm{Na}$ such as 138 $\mathrm{mEq} / \mathrm{l}$ to all patients in a dialysis unit is not an optimal therapy. The optimal family of $\mathrm{C}_{\mathrm{di}} \mathrm{Na}$ values is shown in figure 14 where they can be seen to be matched to the family of $\mathrm{C}_{\mathrm{sp}} \mathrm{Na}$ values. Only in this way can inappropriate diffusive $\mathrm{Na}$ gradients complicating ultrafiltration be avoided.

\section{Errors in Delivery of the Prescribed $\mathrm{C}_{\mathrm{di}} \mathrm{Na}$}

Volumetric proportioning in modern dialysate delivery systems is very precise with an error in conductivity of less than $0.02 \mathrm{mS} / \mathrm{cm}$. However the minimal error in the manufacture of dialysate concentrates is of the order of $\pm 2.5 \%$ or $\pm 4 \mathrm{mEq} / 1$ [Gotch, unpubl. data] of delivered dialysate $\mathrm{Na}$ which translates directly into a similar error in prescribed dialysate $\mathrm{Na}$. A high priority for improving the ultrafiltration prescription should be increasing the accuracy of prescribed dialysate $\mathrm{Na}$ and the error in measured $\mathrm{C}_{\mathrm{p}} \mathrm{Na}$. This is illustrated in figure 15 where the wide range in accuracy of $\mathrm{C}_{\mathrm{di}} \mathrm{Na}$ can be seen to seriously compromise attempts to match $\mathrm{C}_{\mathrm{di}} \mathrm{Na}$ with $\mathrm{C}_{\mathrm{sp}} \mathrm{Na}$. The development of rigorous conductivity-based algorithms to monitor both $\mathrm{C}_{\mathrm{di}} \mathrm{Na}$ and $\mathrm{C}_{\mathrm{p}} \mathrm{Na}$ should be high-priority items to minimize inappropriate diffusive $\mathrm{Na}$ flux with the current therapy. 
Fig. 15. The wide standard deviation in measurement of $\mathrm{C}_{\mathrm{di}} \mathrm{Na}$ and $\mathrm{C}_{\mathrm{p}} \mathrm{Na}$ makes it impossible to avoid inappropriate diffusive flux.

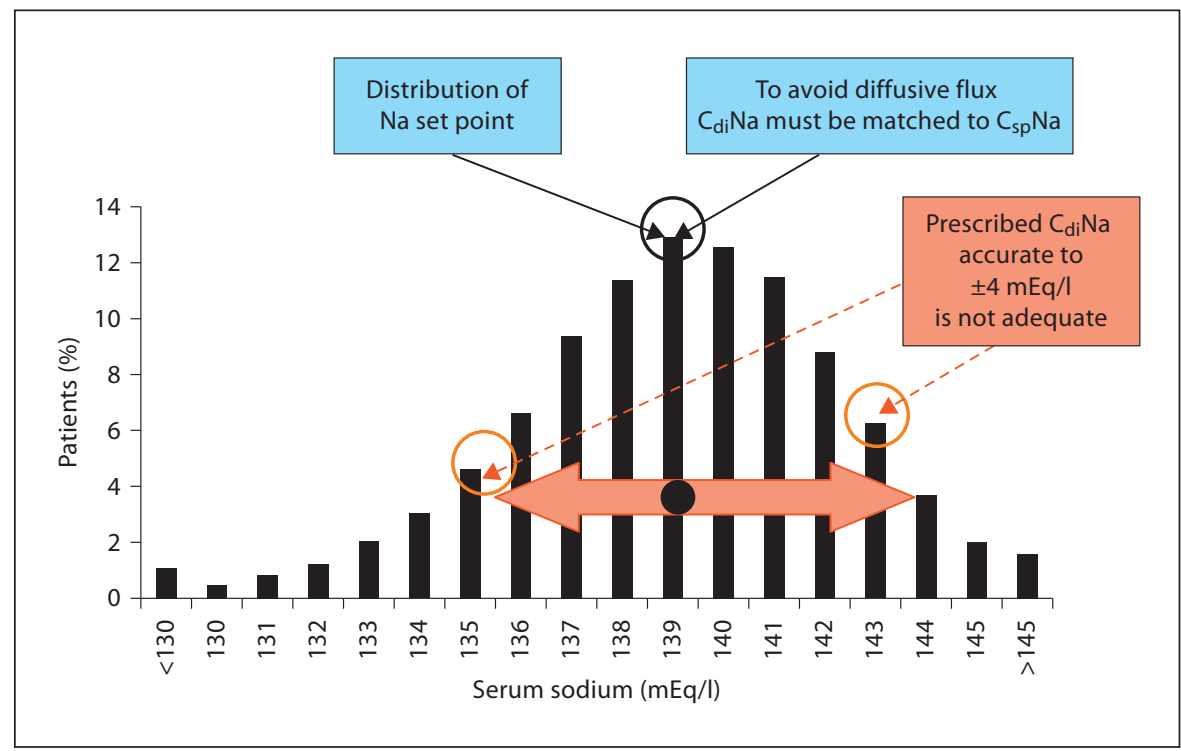

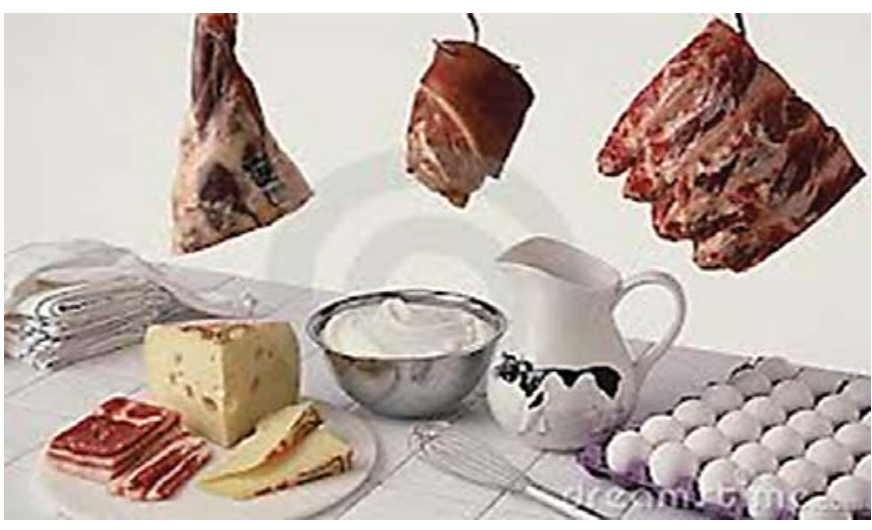

Fig. 16. Phosphate is an essential cell constituent but in dialysis therapy it is one of the few clearly identified major toxins that must be removed by the dialyzer and binders.

\section{Measurement of $V_{\text {ecw }}$}

This is an essential diagnostic tool required to fully optimize management of fluid balance. A very promising approach here is indirect measurement of $\mathrm{V}_{\mathrm{ecw}}$ in the calf to measure resistivity with bioimpedance spectroscopy. The calf is considered the most dependent segment of $\mathrm{V}_{\mathrm{ecw}}$ and therefore the optimal sample site to establish normality of $\mathrm{V}_{\mathrm{ecw}}[26,27]$. Preliminary results are promising that a regression of the form

$$
\Delta \mathrm{BWt}=\alpha\left(\mathrm{R}_{0}-\beta\right)
$$

where $\Delta \mathrm{BWt}$ is the change in body weight required to reach true 'dry body weight', $\mathrm{R}_{0}$ is current calf resistiv- ity and $\beta$ is normal calf resistivity. Such a relationship might provide an exact value for the amount of fluid to be removed to reach dry body weight. A reliable number for the target weight could then be used to establish the rate of ultrafiltration and treatment time required to reach the target in individual patients. Based on the current apparent high frequency of fluid overload, it is likely that treatment times would have to be prolonged in many patients unless a more effective control of $\mathrm{Na}$ intake could be achieved through a more rigorous analysis of $\mathrm{Na}$ overload and effective dietary counseling and optimization of dialysate sodium as discussed above.

It is not possible to set rigid standards on the rate of ultrafiltration until these issues have been successfully resolved and clinical research in these areas should be a high priority recommendation for the improvement of ultrafiltration control in hemodialysis.

\section{Ca, $P$ and Bone Metabolism}

Historically in dialysis therapy quantitative analysis of $\mathrm{Ca}$ and $\mathrm{P}$ transport across the dialyzer membrane has been largely ignored, individualization of dialysate $\mathrm{Ca}$ level has not been considered and $\mathrm{Ca}$ and $\mathrm{P}$ absorption and mass balance have not been considered in reviews of dialysis prescriptions [1-3]. A series of studies quantifying these important relationships have been reported from the Renal Research Institute in New York [28-34] but are not often considered in the discussion of the dialysis prescription [1-3]. As shown in figure $16 \mathrm{P}$ is wide- 
Fig. 17. Examples of the diagnostic use of the PPR for QA of dialysis therapy. From the PPR and PCR the total ingestion of $P$ can be directly calculated and used to help guide $\mathrm{P}$ control. $\mathrm{K}_{\mathrm{r}} \mathrm{U}=$ Renal urea clearance; $\mathrm{Rx}=$ treatment.

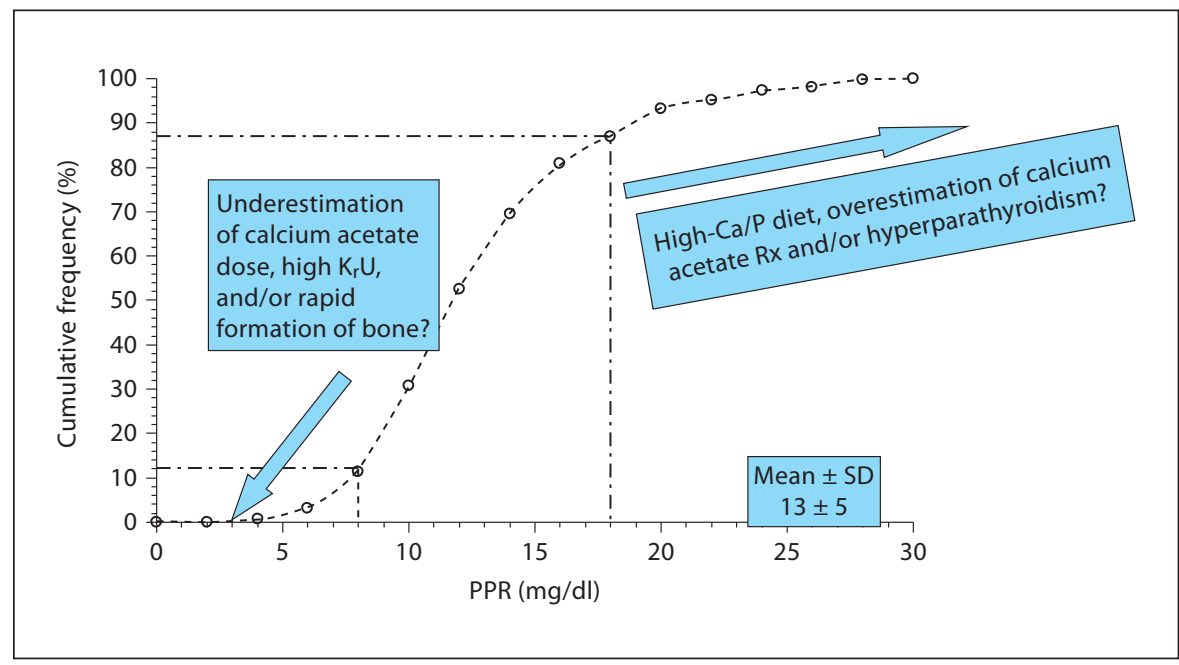

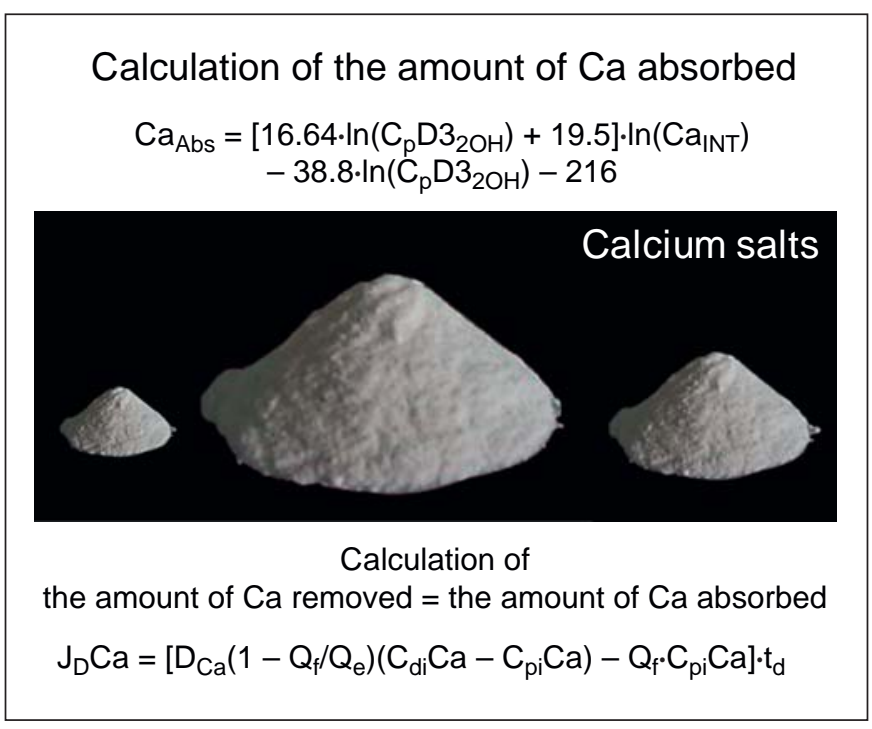

Fig. 18. Calculation of calcium absorbed and removed with calcium kinetic modeling [for more details, see 28-34].

ly distributed in all protein-rich foodstuffs and particularly in dairy products. A combination of a model of $\mathrm{P}$ absorption and removal (phosphate kinetic modeling) combined with UKM permits calculation of PPR - the ratio of phosphorus content to protein content in the ingested diet [34], as shown in figure 17.

We believe clinical analytic data such as in figure 17 combined with PCR are mandatory to rigorously calculate the dose of $\mathrm{P}$ binders and guide dietary counseling with respect to protein and $\mathrm{P}$ intakes, both from dietary and nondietary sources. Figure 18 depicts the published

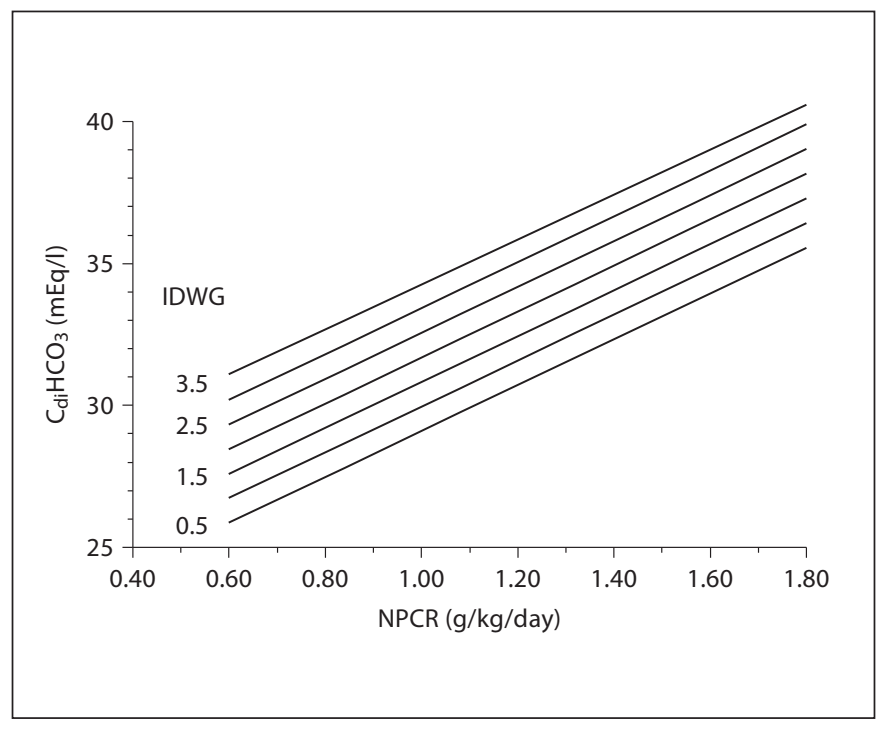

Fig. 19. Solution of acid-base model for $\mathrm{C}_{\mathrm{di}} \mathrm{HCO}_{3}$ as a function of $\mathrm{V}_{\mathrm{U}}=35$ liters, IDWG 0.5-3.5 kg, NPCR 0.6-1.8 g/kg/day and predialysis $\mathrm{CpHCO}_{3} 21 \mathrm{mEq} / \mathrm{l}$. A wide range of $\mathrm{C}_{\mathrm{di}} \mathrm{HCO}_{3}$ is required ranging from 26 to $40 \mathrm{mEq} / \mathrm{l}$ to control predialysis bicarbonate at this level. Equation solved for 2 days interdialytic interval.

calcium absorption and removal equations to target zero Ca mass balance in dialysis as a function of the interacting effects of Ca intake, vitamin D3 doses and the dialysate Ca concentration [34]. In view of the high incidence of coronary artery calcification it would seem prudent to avoid overload of Ca salts and strive for zero Ca mass balance routinely. 


\section{Acid-Base Balance}

None of the recent publications calling for longer $t_{d}$ and $\mathrm{HDF}_{\mathrm{HV}}$ have included recommendations concerning the acid-base balance. A kinetic model of $\mathrm{H}^{+}$balance published 30 years ago [35] showed that the key patient parameters determining the plasma concentration of bicarbonate $\left(\mathrm{C}_{\mathrm{p}} \mathrm{HCO}_{3}\right)$ are PCR, IDWG and $\mathrm{V}_{\mathrm{U}}$. More recently, mortality rates associated with predialysis $\mathrm{C}_{\mathrm{p}} \mathrm{HCO}_{3}$ have been published by DOPPS [36]. The DOPPS results indicate that the mortality risk increases with both significant predialysis metabolic acidosis and alkalosis. In particular predialysis $\mathrm{C}_{\mathrm{p}} \mathrm{HCO}_{3}$ should not be at the upper bounds of the normal range. The acid-base modeling equations published years ago were based on a singlepool variable-volume model of $\mathrm{HCO}_{3}$ distribution in extracellular water and neutral mass balance for $\mathrm{H}^{+}$in the body buffers over the complete dialysis cycle. Solutions of this model for the intradialytic and interdialytic $\mathrm{C}_{\mathrm{p}} \mathrm{HCO}_{3}$ concentration profiles showed these values were quite sensitive to PCR, IDWG and $\mathrm{V}_{\mathrm{U}}$ so that a substantial range of $\mathrm{C}_{\mathrm{di}} \mathrm{HCO}_{3}$ would be required in a dialysis facility to achieve tight control of $\mathrm{C}_{\mathrm{p}} \mathrm{HCO}_{3}$ as shown in figure 19 .

In conclusion, we think that the dialysis prescription can be substantially improved with respect to the control of $\mathrm{Na}$ and water balance, $\mathrm{Ca}, \mathrm{P}$ and bone metabolism and acid-base balance which are key uremic abnormalities not well managed in the current dialysis therapy. Prolongation of treatment time may be necessary to achieve normal fluid volume status particularly when intradialytic hypotension occurs, but we do not believe there is evidence to support a general extension of treatment times to 4 or $5 \mathrm{~h}$ or to routinely prescribe high-volume hemodiafiltration.

\section{Disclosure Statement}

Dr. Kotanko and Dr. Levin hold stock in Fresenius Medical Care.

\section{References}

1 Parker TF, Straube B, Nissenson A, Hakim R, 11 Lowrie E, Lew N: Death risk in hemodialysis Steinman T, Glassock R: Dialysis at a crossroads. II. A call for action. Clin J Am Soc Nephrol 2011;7:1026-1032.

2 Lacson JR, Brunelli: Hemodialysis treatment time: a fresh perspective. Clin J Am Soc Nephrol 2012;10:2522-2530.

3 Locatelli F, Canaud B: Dialysis adequacy: a European perspective. Nephrol Dial Transplant 2012;27:3042-3048.

4 Gotch FA, Sargent JA: A mechanistic analysis of the National Cooperative Dialysis Study (NCDS). Kidney Int 1985;28:526-534.

5 Lowrie EG, Laird NM, Henry RR: Protocol for the National Cooperative Dialysis Study. Kidney Int Suppl 1983;13:11018.

6 Laird NM, Berkey CS, Lowrie EG: Modeling success or failure in the National Cooperative Dialysis Study. Kidney Int Suppl 1973;13: 101-116.

7 Gotch FA, Sargent JA, Keen ML: Whither goest Kt/V? Kidney Int 2000;58:S3-S19.

8 Quinan J: Bostock: the uremic theory. Maryland Med J 1880;7:193.

9 Bright R: Cases and observations illustrative of renal disease accompanied by the secretion of albuminous urine. Guy Hosp Rep 1836;1:338.

10 Daugirdas JT: Second generation logarithmic estimates of single pool variable volume $\mathrm{Kt} / \mathrm{V}$ : an analysis of error. J Am Soc Nephrol 1993;4:1205. patients: the predictive value of commonly measured variables and an evaluation of death rate differences between facilities. Am J Kidney Dis 1990;15:458-483.

12 Saran R, Bragg-Gresham JL, Rayner HC, et al: Nonadherence in hemodialysis: associations with mortality, hospitalization, and practice patterns in the DOPPS. Kidney Int 2003;64:254-262.

13 Saran R, Bragg-Gresham JL, Levin NW, Twardowski ZJ, Wizemann V, Saito A, Kimata N, Gillespie BW, Combe C, Bommer J, Akiba T, Mapes DL, Young EW, Port FK: Longer treatment time and slower ultrafiltration in hemodialysis: associations with reduced mortality in the DOPPS. Kidney Int 2006;69:1222-1228.

14 Eknoyan G, Beck G, Cheung A, Daugirdas J, Greene T, et al: The effect of dialysis dose and membrane flux in maintenance hemodialysis. N Engl J Med 2002;347:2010-2019.

15 Greene T, Daugirdas J, Depner T, et al: Association of achieved dose with mortality in the HEMO study: an example of dose targeting bias. J Am Soc Nephrol 2005;16:3371-3380.

16 Twardowsky Z: Short thrice-weekly hemodialysis is inadequate regardless of small molecule clearance. Int J Artif Organs 2001;27: 252-268.

17 Gotch F: The basic quantifiable parameter of dialysis prescription is $\mathrm{Kt} / \mathrm{V}$ urea; treatment time is determined by the ultrafiltration requirement; all three parameters are of equal importance. Blood Purif 2007;25:18-26.
18 Rocco M, Lockriege R, Beck G, Eggars P, et al: The effects of frequent nocturnal hemodialysis: the frequent hemodialysis network MPCTIRMA; TROA. Kidney Int 2011;60: 1071-1093.

19 Ok E, Asci G, Sevinc O, et al: Comparison of postdilution online hemodiafiltration and hemodialysis (Turkish HDF Study). ERA/ EDTA 2011, LBCT2.

20 Grooteman M, Van den Dorpel R, Bots M, et al: Effect of online hemodiafiltration on allcause mortality and cardiovascular outcomes. J Am Soc Nephrol 2012;23:1087-1096.

21 Gotch F, Panlilio F, Buyaki R, Wang E, Floden T, Levin N: Mechanisms determining the ratio of conductivity clearance to urea clearance. Kidney Int 2004;66(suppl 89):S4-S24.

22 Gotch F, Lam M, Prowitt P, Keen M: Preliminary results with sodium volume modeling of dialysis therapy. Proc Dial Transplant Forum 1980;10:12-17.

23 Edelman IS, Leibman J, O’Meara MP, Birkenfeld LW: Interrelations between serum sodium concentration, serum osmolarity and total exchangeable sodium, total exchangeable potassium and total body water. J Clin Invest 1958;37:1236-1256.

24 Keen ML: The Sodium 'Setpoint': The Relationship to Interdialytic Weight Gain and Blood Pressure in Hemodialysis Patients; doctoral dissertation, University of California, San Francisco, 1997. 
25 Keen ML, Gotch FA: The association of the sodium 'setpoint' to interdialytic weight gain and blood pressure in hemodialysis patients. Int J Artif Organs 2007;30:971-979.

26 Zhu F, Kotanko P, Levin NW: Prediction of dry weight using calf resistivity, results from a validation study. J Am Soc Nephrol 2010; 21:435A.

27 Zhu F, Kotanko P, Handelman GJ, Raimann JG, Lui L, Carter M, Kuhlmann MK, Seibert E, Leonard EF, Levin NW: Estimation of normal hydration in dialysis patients using whole body and calf bioimpedance analysis. Physiol Meas 2011;32:887-892.

28 Gotch FA, Panlilio F, Sergeyeva O, Rosales L, Folden T, Kaysen G, Levin NW: A kinetic model of inorganic phosphorus mass balance in hemodialysis therapy. Blood Purif 2003;21:51-57.
29 Gotch FA, Kotanko P, Handelman G, Levin $\mathrm{N}$ : A kinetic model of calcium mass balance during dialysis therapy. Blood Purif 2007;25: 139-149.

30 Gotch F: What are the potential solutions for the problems with current methods for quantifying hemodialysis? Semin Dial 2008; 21:411-414.

31 Gotch F: Calcium and phosphorus kinetics in hemodialysis therapy; in Ronco C, Cruz DN (eds): Hemodialysis - From Basic Research to Clinical Trials. Contrib Nephrol. Basel, Karger, 2008, pp 210-214.

32 Gotch FA, Levin NW, Kotanko P: Calcium balance in dialysis is best managed by adjusting dialysate calcium guided by kinetic modeling of the interrelationship between calcium intake, dose of vitamin D analogues and the dialysate calcium concentration. Blood Purif 2010;29:163-176.
3 Gotch FA: Pro/Con debate: the calculation on calcium balance in dialysis lowers the $\mathrm{di}$ alysate calcium concentrations (pro part). Nephrol Dial Transplant 2009;24:29942996.

34 Gotch FA, Kotanko P, Thijssen S, Levin NW: The KDIGO guideline for dialysate calcium will result in an increased incidence of calcium accumulation in hemodialysis patients. Kidney Int 2010;78:343-350.

35 Gotch F, Sargent J, Keen M: Hydrogen balance in dialysis therapy. Artif Organs 1982; 6:386-394

36 Bommer J, Locatelli F, Sudtida S, Keen M, Goodkin D, et al: Association of serum bicarbonate levels with risk of mortality and hospitalization in the Dialysis Outcomes and Practice Patterns Study (DOPPS). Am J Kidney Dis 2004;44:661-671. 